\title{
STORAGE OF WIND POWER ENERGY
}

\author{
Andrzej Tywoniuk, Zbigniew Skorupka \\ Eukasiewicz Research Network - Institute of Aviation, \\ Krakowska Av. 110/114, 02-256 Warsaw, Poland \\ tel.: +48228460011 ext. 219, 657, fax: +48943426753 \\ e-mail: andrzej.tywoniuk@ilot.edu.pl,zbigniew.skorupka@ilot.edu.pl
}

\begin{abstract}
There has been a big increase in production and investments in wind turbines and wind farms in last 20 years. New generation of wind turbines is more reliable than from 1980's are, which necessary condition is energy production is to play an important role among renewable energy sources. Over the last 30 years, the size of wind turbines increased 7 times, as nominal power increased nearly 14 times. At present, turbines capable of producing over $10 \mathrm{MW}$ of power are being developed. The main reason for continued growth of turbines sizes is to minimize the energy cost per kilowatt-hour. However, it is worth remembering that according to the „square-cube law”, there is a maximum size after the surpassing of witch the cost of ever-larger turbines would grow faster than financial gain from the increased size. In this article, authors present energy storage methods and devices for wind power plants and cost-effectiveness of the individual energy storage methods. Authors also present data about energy storage efficiency and groups of energy storage devices for wind power plants such as: compressed-air power stations + gas turbine (CAES), utilizing underground wells, pumped storage power plants, rechargeable batteries (lithium-ion, lead-acid, sodium sulphur, VRB, zinc-flow, zinc-air, zinc-air), flywheels, hydrogen production and storage systems, superconducting magnetic energy storage (SMES), electrostatic storage-electrolytic capacitors.
\end{abstract}

Keywords: energy storage, wind energy, renewable energy, energy storage methods

\section{Introduction}

Storage of electricity is a set of methods (Fig. 1) that allow the storage of electric energy or other forms of energy (converted from electricity) on a large scale within the power grid. Energy can be stored when production outweighs consumption, and used when consumption outweighs production. As a result, power generation from a power plant does not need to be adjusted for momentary usage. Energy demand changes over the course of a day, so energy storage makes using renewable energy sources easier and more efficient by setting their production to a constant level. This eliminates the need to adapt to momentary demand and to use energy sources whose output fluctuates dramatically throughout the day, as it does in the case of wind energy.

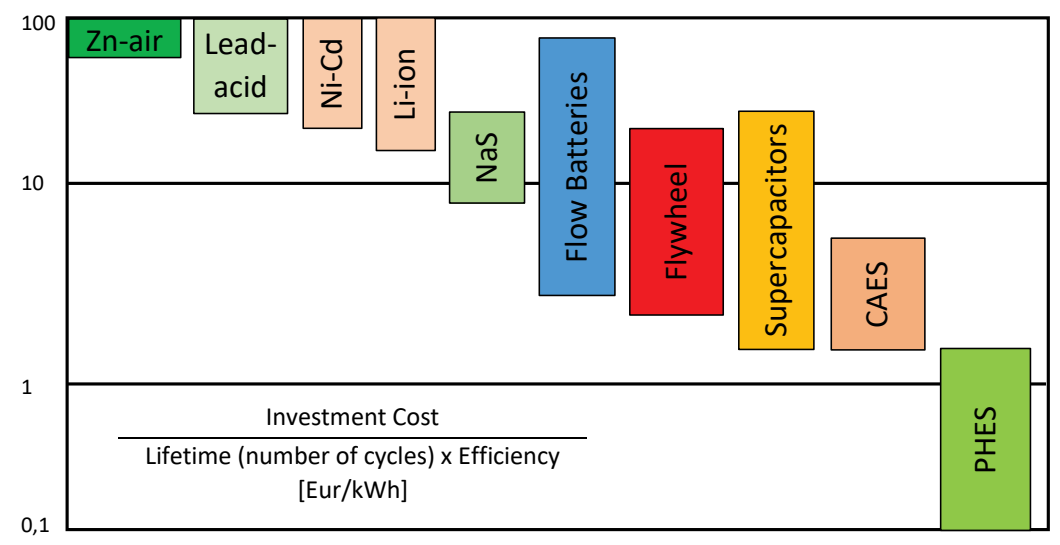

Fig. 1. Types and the cost-effectiveness of the individual energy storage methods [4] 


\section{Energy storage types}

Energy storage devices for wind power plants can be divided into the following groups:

a) Battery Energy Storage (BES) - rechargeable batteries,

b) Supercapacitor Energy Storage (SES) - electrolytic capacitors,

c) Superconducting Magnetic Energy Storage (SMES) - superconducting coils,

d) Flywheel Energy Storage (FES) - mechanical energy storage,

e) Pumped Hydroelectric Energy Storage (PHES) - hydroelectric power plant,

f) Hydrogen Energy Storage (HES) - gas hydrogen and fuel cells,

g) Compressed Air Energy Storage (CAES) - compressed-air storage and gas turbines.

a) Battery Energy Storage (BES)

Battery energy storage (BES) is nowadays most common method of energy storage in general. It is used in the wind energy due to its properties:

- modularity (ease of integrating it with the grid),

- placement flexibility (low requirements on external infrastructure cooperation),

- low latency (seconds),

- low maintenance.

Due to the above the battery storage can be installed in near proximity (or even inside) of the wind turbines.

The Battery Energy Storage uses rechargeable batteries as the means of storage. The technology itself is mature enough to be reliable. In addition, there are various types of batteries used in the energy storage facilities (Tab. 1). The variety of the battery solutions is wide so only brief overview is presented in this article.

Tab. 1. Various batteries technical data [6]

\begin{tabular}{|l|c|c|c|c|c|}
\hline \multicolumn{1}{|c|}{ Battery Type } & $\begin{array}{c}\text { Power } \\
{[\mathrm{MW}]}\end{array}$ & $\begin{array}{c}\text { Discharge } \\
\text { time }\end{array}$ & $\begin{array}{c}\text { Efficiency } \\
{[\%]}\end{array}$ & Lifetime & $\begin{array}{c}\text { Investment } \\
\text { cost } \\
{[\mathrm{USD} / \mathrm{kW}]}\end{array}$ \\
\hline Lithum-ion & 5 & 15 min to few h & $90(\mathrm{DC})$ & 15 years & $4000-5000$ \\
\hline Lead-acid & $3-20$ & $10 \mathrm{~s}$ to few h & $\begin{array}{c}75-80(\mathrm{DC}) \\
70-75(\mathrm{AC})\end{array}$ & $4-8$ years & $1740-2580$ \\
\hline Sodium-sulphate & 35 & $8 \mathrm{~h}$ & $80-85(\mathrm{DC})$ & 15 years & $1850-2150$ \\
\hline VRB flow battery & 4 & $4-8 \mathrm{~h}$ & $\begin{array}{c}75-80(\mathrm{DC}) \\
63-68(\mathrm{AC})\end{array}$ & 10 years & $7000-8200$ \\
\hline Zinc-bromine flow battery & $0.04-$ & $2-4 \mathrm{~h}$ & $\begin{array}{c}75-80(\mathrm{DC}) \\
60-70(\mathrm{AC})\end{array}$ & 20 years & $5100-5600$ \\
\hline Iron-chormium redox flow battery & $<-10$ & $2-4 \mathrm{~h}$ & $50-65$ & 20 years & $200-2500$ \\
\hline Zinc-air & $0.02-10$ & $3-4 \mathrm{~h}$ & $40-60$ & Several k-cycles & $3000-5000$ \\
\hline
\end{tabular}

Nowadays rated capacity (power) of the batteries installed near the wind power plants is not exceeding the several dozen of MW. The main economic disadvantage of the batteries is quite high unit cost in relation to battery power - what should change in the future due to the technology advantages.

The example of use the battery energy storage is $32 \mathrm{MW}$ installation in Laurel Mountain Farm, West Virginia (USA) launched in 2011. The total installed power of the farm is $98 \mathrm{MW}$. Other examples are in Tab. 2. 
Tab. 2. Examples of Battery Energy Storage facilities

\begin{tabular}{|c|c|c|c|c|c|}
\hline Name (location) & Year & $\begin{array}{l}\text { Rated } \\
\text { Power }\end{array}$ & Capacity & Usage & Remarks \\
\hline \multicolumn{6}{|l|}{ Lead-acid batteries } \\
\hline BEWAG, Berlin, Germany & 1986 & $17 \mathrm{MW}$ & $14 \mathrm{MWh}$ & Reserve, Frequency Control & Closed in 1996 \\
\hline SCE, Chino, USA & 1988 & $10 \mathrm{MW}$ & $40 \mathrm{MWh}$ & Multiuse & Closed in 1995 \\
\hline \multicolumn{6}{|l|}{ Cadmium-nickel Batteries } \\
\hline Golden Valley, Alaska, USA & 2003 & $27 \mathrm{MW}$ & $14 \mathrm{MWh}$ & Reserve, Frequency Control & $\begin{array}{l}\text { Max. power } \\
40 \mathrm{MW}\end{array}$ \\
\hline \multicolumn{6}{|l|}{ Sodium-sulphate batteries } \\
\hline Tsuanshima & 1997 & $6 \mathrm{MW}$ & $48 \mathrm{MWh}$ & \multirow{2}{*}{$\begin{array}{l}\text { Load compensation, } \\
\text { Peak smoothing }\end{array}$} & \\
\hline Hitachi & 2004 & $9 \mathrm{MW}$ & $57 \mathrm{MWh}$ & & \\
\hline \multicolumn{6}{|l|}{ Flow batteries } \\
\hline Imajuku, Japan & 1990 & $1 \mathrm{MW}$ & $4 \mathrm{MWh}$ & Demonstrator & \multirow{3}{*}{$3 \mathrm{MW}$ in $1.5 \mathrm{~s}$} \\
\hline Osaka, Japan & 2001 & $1.5 \mathrm{MW}$ & $1.5 \mathrm{MWh}$ & Peak smoothing, UPS & \\
\hline Pacifcorp., Utah, USA & 2003 & $250 \mathrm{~kW}$ & $2 \mathrm{MWh}$ & Peak smoothing & \\
\hline
\end{tabular}

\section{b) Supercapacitor Energy Storage (SES)}

One of the newest solutions in the energy storage is the supercapacitors capable of operation with high currents (up to kA). Supercapacitors have large capacities, high durability, and can operate in wide temperature range. Supercapacitor is in a sense a hybrid of the electrolytic capacitor and battery. Due to the specific construction, it is capable of storing up to few thousand of farads in relatively small package and is able to provide high energies in short time. Both of the mentioned parameters (high energy density and high-power density) define the supercapacitor as a very capable energy storage.

The general principle of capacitor operation (Fig. 2) is the accumulation of electrical charges within ElectricDoubleLayer - ELD, which is formed at the electrode-electrolyte border. Capacity of the device is directly proportional to the area of the electrodes and counter proportional to the distance between them. Supercapacitors are designed to have the largest area of the electrodes and smallest distances in the same time by using carbon nanotubes where the area of one gram of the electrode is around $2000 \mathrm{~m}^{2}$ giving gigantic area and therefore very large capacity in small package.

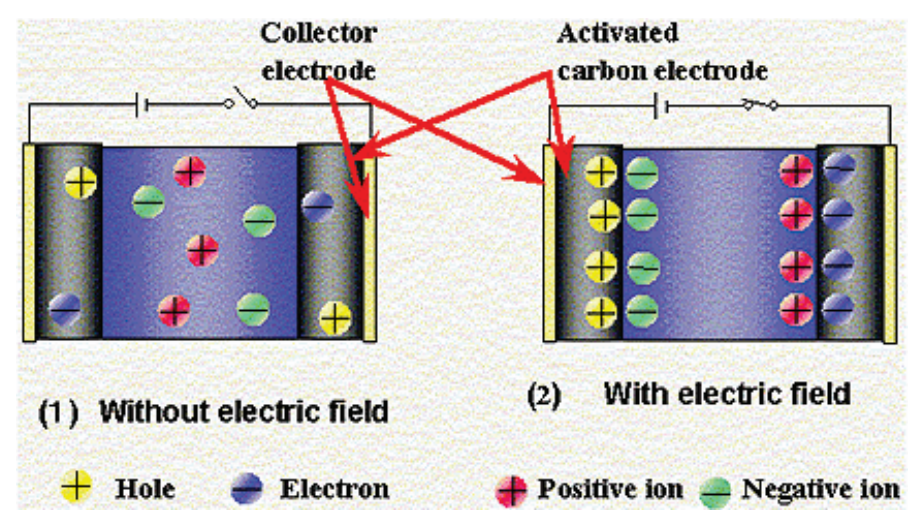

Fig. 2. Construction and operation principle of the capacitor (including supercapacitors) (1) chaotic distribution of electric charge in discharged capacitor, (2) ordered distribution of the electric charge and ELD in charged capacitor [7] 
The supercapacitors are used in the wind energy as buffers capable to acquire momentary power jumps (present due to the inconstant nature of the wind power technology) and as the power backup while there is a power loss of any kind.

Main advantage of the supercapacitor is efficiency around $90 \%$, rated power up to $10 \mathrm{MW}$, large (up to 500 000) charge-discharge cycles, and a short charge time. Disadvantages are mainly low specific energy and high cost - which is constantly lowering due to the developments in the technology.

\section{c) Superconducting Magnetic Energy Storage (SMES)}

Superconducting magnetic energy storage (SMES) is a device which store energy in magnetic field created by the direct current flowing in coil cryogenically cooled in order to achieve superconducting capabilities (Fig. 3). When charged the coil current does not disappear so the energy in its magnetic field can be stored indefinitely. The stored energy can be released to the grid with small loss (2 to 3\%) when the device is discharged. The released power can be AC or DC depending on the conditioning system used. SMES is a high efficiency energy storage (up to $95 \%$ ). Main disadvantage of the system is the cost of cooling system and the price of the superconducting materials as well. In addition, the existence of the strong magnetic field can influence the living organisms - the proper analyses are not yet conclusive but the general knowledge can justify the concerns - so the proper buffer zones are needed in order to guarantee safety of the system. As advantages, the short time of charge/discharge and low latency of energy release can be addressed. In addition, the main components of the system (coils, cooling system and conditioners) are stationary what assures the high reliability of the system.

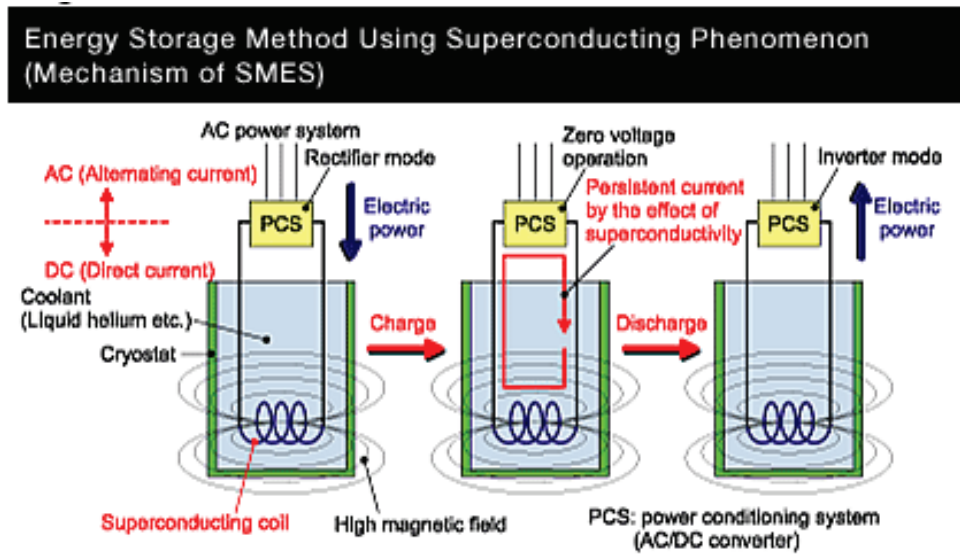

Fig. 3. SMES operation principle [3]

\section{d) Flywheel Energy Storage (FES)}

Flywheel, which is in general, the high inertia device used as the short time mechanical (kinetic) energy storage. Basic operation of the flywheel as energy storage base on the spinning it when there is a surplus of energy and braking it when the energy is needed. Maximal amount of stored energy is mostly defined by the highest flywheel velocity, which is limited by the material strength and shape of the flywheel itself. Modern flywheels made out of the composite materials can achieve the energy density comparable to the accumulators.

There are two main types of the flywheels - low and high speed. Low speed flywheels can be spin up to $1000 \mathrm{rpm}$ and are mostly steel. High speed ones are made out of the composite materials and can be reach up to $10000 \mathrm{rpm}$. In order to withstand the high revolution rates the magnetic bearings are used for minimizing the friction, also flywheels are placed in low pressure close to vacuum conditions for the same reason. Flywheels can store up to 0.75-1.65 MW, have high efficiency reaching 93\%, and high lifetime - even 20 years. The main advantages of this kind of 
energy storage are high-energy density, high number of charge-discharge cycles, quick charge, and quick discharge (in seconds) accompanied with very low latency. Disadvantages are the low specific energy, high losses when idle and potential operation dangers due to the high rotational speeds and inertias used. This high discharge rate (even when idle) reaches up to $10 \%$ per hour makes the flywheel energy storage reasonable for quick use of the stored energy.

Flywheels are not meant as the economical replacement of other energy storage types but rather as the solution improving the electric energy quality for the photovoltaic and wind energy sources as well as the latency compensation for the diesel generators. Pilot programmes were introduced on Azores Islands and in Coral Bay Australia.
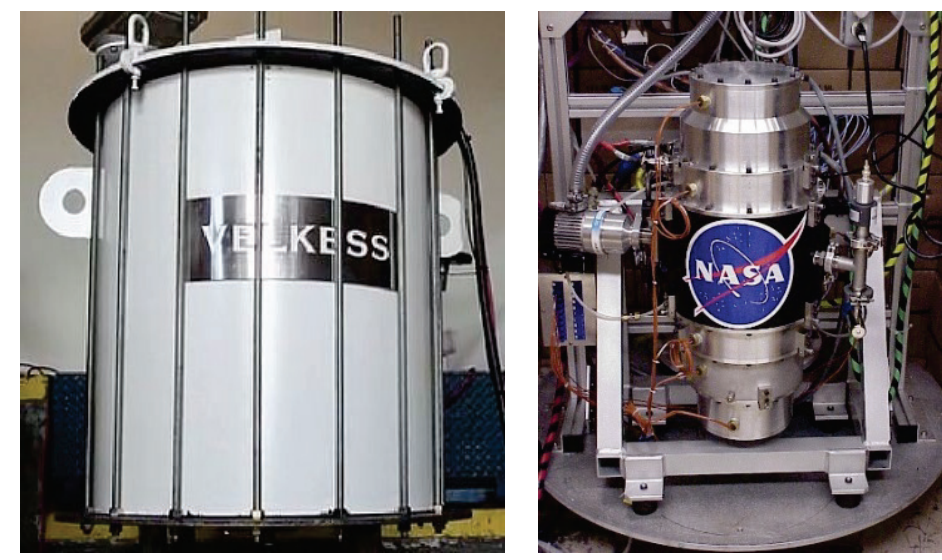

Fig. 4. Examples of the flywheel energy storage: Velkess - left [1], NASA G2 -right [8]

\section{e) Pumped Hydroelectric Energy Storage (PHES)}

Pumped Hydroelectric Energy Storage is sometimes wrongly called a power station due to the resemblance to the pure hydroelectric power plant. The PHES (Fig. 5) is an energy storage utilizing two large tanks of water (natural or artificial) one above the other, pump and the hydroelectric turbine. The energy storage process consists of two phases: pumping water form lower to upper tank when the energy is in low demand and therefore there is a surplus, and when there is increased energy demand the water is released from the upper tank via the turbine to the lower one generating electricity. The method is highly lossy (only $70 \%$ of the initial energy is recovered) but it serves a purpose of equalizing the grid energy utilization balancing. The PHES has vast storage capacities and is fairly quick to release the energy on demand - full power is achieved in minutes.

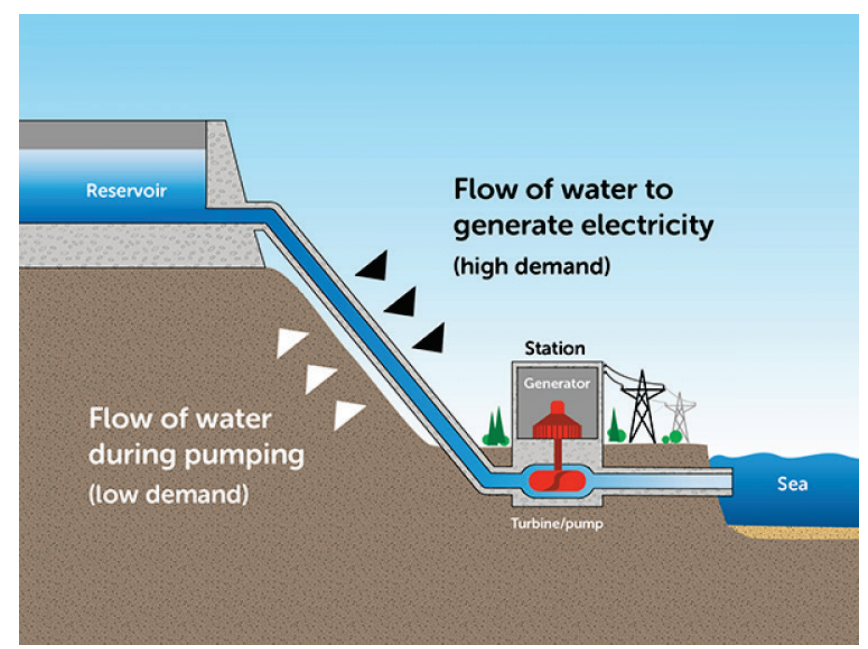

Fig. 5. Pumped Hydroelectric Energy Storage (PHES) operational principle [2] 
Main advantage of the PHES is its energy storage capabilities (up to $1000 \mathrm{MW}$ ) but it requires large bodies of water in order to operate. The PHES is used for storing energy from any kind of power plant especially the nuclear (not constant energy demand) and renewable (not constant energy production).

\section{f) Hydrogen Energy Storage (HES)}

Another method of wind energy storage is the use of electrolysis process in order to obtain hydrogen and store it for later use. The electrolysis is a process in which water molecule is divided into oxygen and diatomic hydrogen by using the electric current. Produced hydrogen is a good source of energy due to its low flash point, wide range of combustibility, high auto-ignition temperature, and most important $\mathrm{CO}_{2}$ free combustion so important due to the climate related issues.

Hydrogen storage is a complicated task no matter what method will be used (solid, fluid or gas state). The main issue is that hydrogen atom is so small it can penetrate almost of the materials flowing out of the containers or accumulating between material layers. Hydrogen, due to its high reactivity with other materials, can also form corrosive compounds with the container materials. Therefore, hydrogen storing is so challenging and expensive. Pure hydrogen as a fuel is used in internal combustion engines as replacement to fossil fuels but its potential is not fully used. Hydrogen is also neutral to the environment what makes it much environmentally friendly than other combustible fuels.

Electrolysis and production of the hydrogen is well recognised; and commonly used in countries such Island, Brazil or Canada where access to cheap electricity is virtually unlimited. The US Department of Energy estimated the price of $\$ 2.85$ for the one kilogram of hydrogen produced in electrolysis process.

More effective solution, than the hydrogen combusting engines, is the fuel cells, which directly convert chemical energy for electric energy and heat, using the electrochemical reactions. Main component of the fuel cell are two active electrodes: fuel anode, oxidizer cathode, and electrolyte between them, which can pass through ions only. The general principle of operation of various fuel cells is similar; the main differences are the type of electrolyte and operation temperature. Most common fuel cell type is membrane based one - PEMFC („Proton Exchange Membrane Fuel Cell").

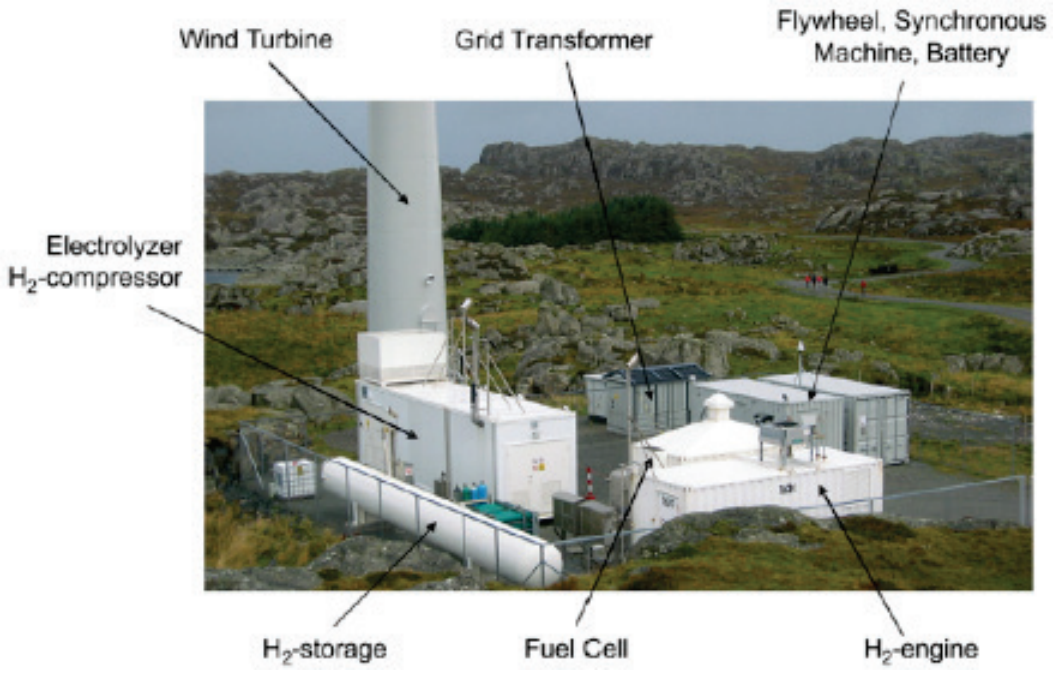

Fig. 6. Utsira wind power plant overview [9]

A very good example of hydrogen-based energy storage is a wind power plant located on the Norvegian island of Utsira (Fig. 6) where main electricity production is made by two wind 
turbines. When energy surplus occurs, the electricity is routed to the electrolyser where around $10 \mathrm{Nm}^{3} / \mathrm{h}$ of hydrogen is produced and stored in tanks of full capacity $2400 \mathrm{Nm}^{3}$ under 200 bars of pressure. The installation is supplying the hydrogen to the $10 \mathrm{~kW}$ fuel cell and $55 \mathrm{~kW}$ hydrogen combustion engine. As latency protector, the flywheel energy storage is also used.

\section{g) Compressed Air Energy Storage (CAES)}

Compressed Air Energy Storage is similar to the PHES and HES with compressed air as storage medium. The basic operation is to compress air using high efficiency compressors during energy surplus and expand powering the turbine(s) when there is an energy demand. Compressed air can be stored in underground caverns or pressure tanks - similar to the HES. As the air is commonly present and is environmentally neutral CAES can be named cleanest of all the energy storage technologies.

The power capacity of this type of solution ranges from 15 to $400 \mathrm{MW}$, and it has the enormous advantage of a lifetime of up to 35 years and a relatively small investment cost compared to other energy storage systems from wind power plants, i.e. $600-750 \mathrm{USD} / \mathrm{kW}$.

The method of storing wind energy in a compressed-air power plant is the most promising one, and it has been proven that in laboratory conditions compression and expansion can be performed with efficiency close to $100 \%$. For commercial use, such performance is unattainable and real performance ranges from 54 to $88 \%$, due to the high temperatures of the compressed air (up to $800^{\circ} \mathrm{C}$ ), resulting in heat transfer losses. Further energy losses result from the cooling of the air used to drive the generator during the operation of the piston engine or turbine. In practical applications, compressed-air power stations use the compressed air to charge up a gas turbine. In such cases, about $35 \%$ comes from gas combustion and the rest from compressed air. In order to increase the efficiency of this form of energy storage, CAES systems are equipped with heat exchangers and condenser systems.

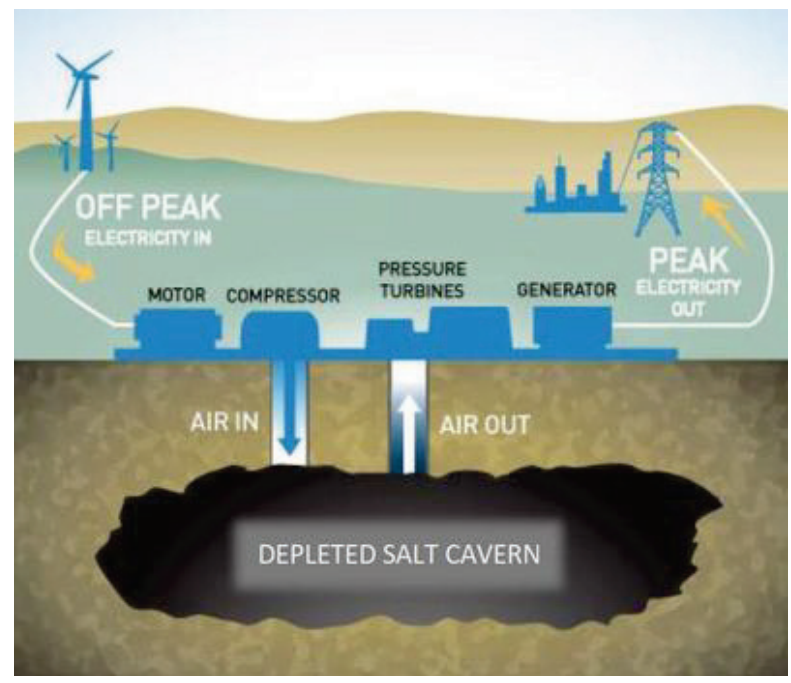

Fig. 7. CAES principle of operation. Note that the air pressure ranges from 50 to 70 bar [5]

There are a number of CAES specific installation solutions that are differentiated by:

a) the location of the compressed air tank (ground or underground),

b) heating system (conventional, heat recovery or adiabatic),

c) auxiliary fuel used in the installation (natural gas, LPG, light diesel or without any auxiliary fuel).

CAES installations utilizing an underground tank may reach higher power (up to hundreds of MW) and thus have resulting significance for practical applications. Two such installations are currently in operation worldwide (data from 2012). The first one, of $321 \mathrm{MW}$, is located in 
Huntorf (northern Germany), while the second is located in McIntosh, Alabama, USA. The German installation, unlike the American one, is not equipped with a recuperator, which allows exhaust gas from the outlet of the gas turbine to heat the air flowing from the tank into the combustion chamber.

Huntorf was built in 1978 to provide the black-start of a nearby nuclear power plant and to provide inexpensive peak power. Originally, the power plant was designed to deliver energy for two hours, but subsequent modifications extended this time to three hours, a result of the development of wind power in northern Germany. The underground part of the power plant consists of two salt caverns of about $150000 \mathrm{~m}^{3}$ in volume each, and the working pressure is in the range of 50-70 bars. At the Huntorf plant, the recuperators were not used to minimize the start-up time, although that would increase the energy efficiency, which is now at $42 \%$. The reliability of the plant over 30 years of working time was about $99 \%$.

\section{Summary}

There are various types of energy storage methods, which are used nowadays. The choice of the type of energy storage is based mainly on maturity of technology, its cost and natural conditions present onsite. For example, there is a better chance to build PHES energy storage when hill and the body of water is present but the CAES is more reasonable when near the energy source large cavern or unused mine is present.

On the other hand, if there is a need to store energy and to have the system, which controls quality of the power-to-grid delivery (peak control, frequency control) the flywheel, seems to be correct solution.

As stated before the variety of the energy storage systems gives nowadays flexibility to deliver correct solution to the needs of the modern renewable energy sources such as wind power plants.

Rapid technological advances in the energy storage systems will result in future development of new systems and further maturing and optimization of existing ones.

\section{References}

[1] Hewitt, J., The Velkess Flywheel: A more flexible energy storage technology, https://phys.org/ news/2013-04-velkess-flywheel-flexible-energy-storage.html, 12.04.2013.

[2] Kenning, T., Energy Australia ponders world's largest seawater pumped hydro energy storage plant, https://www.energy-storage.news/news/energyaustralia-ponders-worlds-largestseawater-pumped-hydro-energy-storage, 22.02.2017.

[3] Nomura, S., Storage Technology that Applies Superconductivity, https://www.meiji.ac.jp/cip/ english/frontline/nomura/index.html, Meiji University, Tokyo.

[4] Płaneta, B., Sobótka, K., Magazynowanie lub komplementarne wykorzystywanie energii elektrowni wiatrowych, Nowa Energia, Racibórz 2010.

[5] Ryan, C., Hydrostor launches new Terra bulk energy storage system, published 18.02.2017, https://www.energy-storage.news/news/hydrostor-launches-new-terra-bulk-energy-storagesystem, 18.02.2017.

[6] Shinichi, I., Prospects for Large-Scale Energy Storage in Decarbonised Power Grids, International Energy Agency, Paris 2009.

[7] Endo Laboratory (Shinshu University) web page, http://endomoribu.shinshu-u.ac.jp/research/ capacitor/index.html, Nagano.

[8] Research \& Technology 2004, NASA/TM-2005-213419, Cleveland, Ohio, June 2005.

[9] Utsira Wind Power and Hydrogen Plant, IPHE Renewable Hydrogen Report, 03.2011. Manuscript received 16 September 2019; approved for printing 12 December 2019 